\title{
A study of the structure-activity relationship of oligomeric ellagitannins on ruminal fermentation in vitro
}

\author{
Nicolas Baert, ${ }^{* 1}$ Wilbert F. Pellikaan, $\dagger$ Maarit Karonen, ${ }^{*}$ and Juha-Pekka Salminen* \\ *Laboratory of Organic Chemistry and Chemical Biology, Department of Chemistry, University of Turku, Turku Fl-20014, Finland \\ †Animal Nutrition Group, Department of Animal Sciences, Wageningen University, PO Box 338, NL-6700 AH Wageningen, the Netherlands
}

\section{ABSTRACT}

The aim of this study was to investigate how the degree of oligomerization of ellagitannins (ET) influences their ability to alter ruminal fermentation. Dimeric to heptameric ET were isolated from rosebay willowherb (Epilobium angustifolium) flowers and purified. Ellagitannins were tested in vitro on a mixture of grass silage and buffered rumen fluid. Total gas production was measured in real time using an automated pressure evaluation system. Methane production was monitored at regular interval by gas chromatography for $72 \mathrm{~h}$. The effect of ET was evaluated on 2 sources of rumen fluid using a randomized block design. Ammonia nitrogen, volatile fatty acid concentration, and $\mathrm{pH}$ were measured at the end of the experiment. Results show that oligomeric ET decreased gas production and total volatile fatty acid concentration proportionally to their degree of oligomerization. Methane production was also decreased by all the tested compounds and dimer was less effective than the larger ET, which showed similar levels of activity. Additionally, willowherb's oligomeric ET decreased ammonia-nitrogen and branched-chain volatile fatty acid concentrations, thus indicating reduced protein degradation by ruminal bacteria. This effect showed a quadratic relationship with the degree of oligomerization and was maximal with the tetramer. In conclusion, this study shows that the degree of oligomerization of ET has more than a simple linear effect on fermentation parameters in vitro. Large oligomers, in fact, have more detrimental effects on volatile fatty acid and gas production than small ones, while being similarly effective at inhibiting methane production.

Key words: gas production technique, willowherb, methane, structure-activity relationship

Received February 22, 2016.

Accepted June 17, 2016.

${ }^{1}$ Corresponding author: nicolas.baert@utu.fi

\section{INTRODUCTION}

The livestock sector contributes to $14.5 \%$ of the global anthropogenic greenhouse gas emissions and $44 \%$ of these emissions (in $\mathrm{CO}_{2}$ equivalent) are in the form of methane $\left(\mathrm{CH}_{4}\right.$; Gerber et al., 2013). Livestock-related $\mathrm{CH}_{4}$ is mainly generated by enteric fermentation and manure management, which together contribute to $44 \%$ (in $\mathrm{CO}_{2}$ equivalent) of the global anthropogenic $\mathrm{CH}_{4}$ emissions, thus making livestock the largest source of anthropogenic $\mathrm{CH}_{4}$ (O'Mara, 2011; Gerber et al., 2013; US Environmental Protection Agency, 2015). Although $\mathrm{CH}_{4}$ from enteric fermentation is a natural by-product of the digestive processes of ruminants, it represents a loss of 2 to $12 \%$ of the animal's gross energy intake (Johnson and Johnson, 1995; McAllister et al., 1996). Methane is synthesized by methanogenic archaea using mainly $\mathrm{CO}_{2}$ and dihydrogen $\left(\mathrm{H}_{2}\right)$ that are produced by anaerobic fermentation of carbohydrates that takes place in the rumen (Moss et al., 2000; Patra, 2012). Methane is then eructed by the animals and released into the atmosphere. Various $\mathrm{CH}_{4}$ mitigation strategies have been studied, and among them, the use of plant secondary metabolites as dietary inhibitors of methanogenesis has shown positive results (Mueller-Harvey, 2006; Patra and Saxena, 2010; Patra, 2012). Tannins, in particular, have been extensively tested both in vivo and in vitro (Woodward et al., 2001; Śliwiński et al., 2002; Waghorn et al., 2002). However, the structureactivity relationships that underlie the mechanisms of action of tannins in the rumen have only begun to be investigated recently (Bhatta et al., 2009; Hatew et al., 2016).

Tannins are plant polyphenolic secondary metabolites that are traditionally divided into 2 major chemical families: hydrolysable tannins (HT) and proanthocyanidins (PA, also known as condensed tannins) (Quideau, 2013). Hydrolysable tannins are characterized by a central polyol (usually D-glucose) esterified by gallic acid molecules. Hydrolysable tannins can be further divided into 2 subgroups: galloyl derivatives and ET. Ellagitannins are synthetized by plants from gal- 
loyl glucoses by the oxidative coupling of galloyl groups that forms the characteristic hexahydroxydiphenoyl group (Mueller-Harvey, 2001). Proanthocyanidins, on the other hand, are polymers of flavan-3-ol units linked together mainly by carbon-carbon bonds (Schofield et al., 2001). Those 2 classes of molecules (HT and PA) possess very contrasting structures and have been shown to exert distinct levels of activity on the various steps of methanogenesis (Pellikaan et al., 2011b; Jayanegara et al., 2015; Saminathan et al., 2015; Hatew et al., 2016). In vitro experiments have shown that both HT and PA can have at least 3 different and complementary modes of action on ruminal methanogenesis. First, they can bind to fibers and decrease their degradability by ruminal microorganisms, thus diminishing the production of $\mathrm{H}_{2}$, which is the limiting substrate of $\mathrm{CH}_{4}$ synthesis by methanogens (Tavendale et al., 2005; Theodoridou et al., 2011; Jayanegara et al., 2015). Second, tannins can impair protozoal activity, which (a) leads to a decrease in $\mathrm{H}_{2}$ partial pressure in the rumen, and (b) may concurrently affect protozoa-associated methanogens, thus hampering $\mathrm{CH}_{4}$ synthesis (Kamra et al., 2006; Bhatta et al., 2009; Morgavi et al., 2010). Finally, PA and HT have been hypothesized to inhibit the activities of methanogens directly and specifically (Kamra et al., 2006; Theodoridou et al., 2011; Jayanegara et al., 2012; Bhatta et al., 2013).

In the 19th century, rosebay willowherb (Epilobium angustifolium) was reportedly used by Finnish farmers to increase milk production of dairy cows (Lönnrot et al., 2002). Since the late 1990s, the plant has been known to contain the oligomeric macrocyclic ET oenothein B and A in large quantities (Ducrey et al., 1997). In a recent study, we found that it contained even larger oligomers, at least up to heptamer (Baert et al., 2015). Whether the increased milk production can be attributed to those ET or not still remains to be proven. Nevertheless, the series of tellimagrandin I (TI)-based oligomeric ET (Figure 1) represents an ideal model to test, for the first time, the effect of the degree of oligomerization on the anti-methanogenic activity of ET.

Unravelling the structural components involved in the anti-methanogenic activity of tannins is relevant because it would permit a rational selection of optimal forages based on their tannin fingerprints. One way to achieve this goal in a time- and cost-effective way is to test pure tannin molecules in an in vitro system that emulates ruminal fermentation. Unfortunately, PA larger than trimer are practically impossible to obtain as pure molecules because plants usually produce PA as complex mixtures of polymers that cannot be separated by the current chromatographic methods (Karonen et al., 2004; Mansoor et al., 2015). For that reason, the only structure-activity studies on the anti-methanogenic effect of PA have been performed using purified fractions of PA-rich extracts of contrasting mean degree of polymerization and procyanidin/prodelphinidin ratio (Saminathan et al., 2015; Hatew et al., 2016). Hydrolysable tannins, however, can be more easily isolated as pure molecules. Nevertheless, to the best of our
(A)
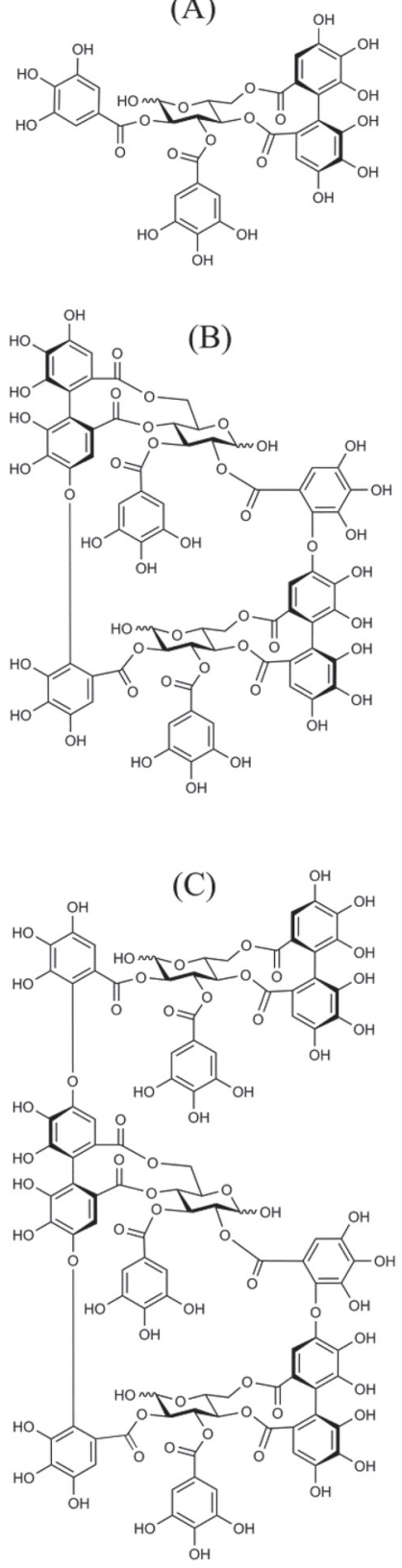

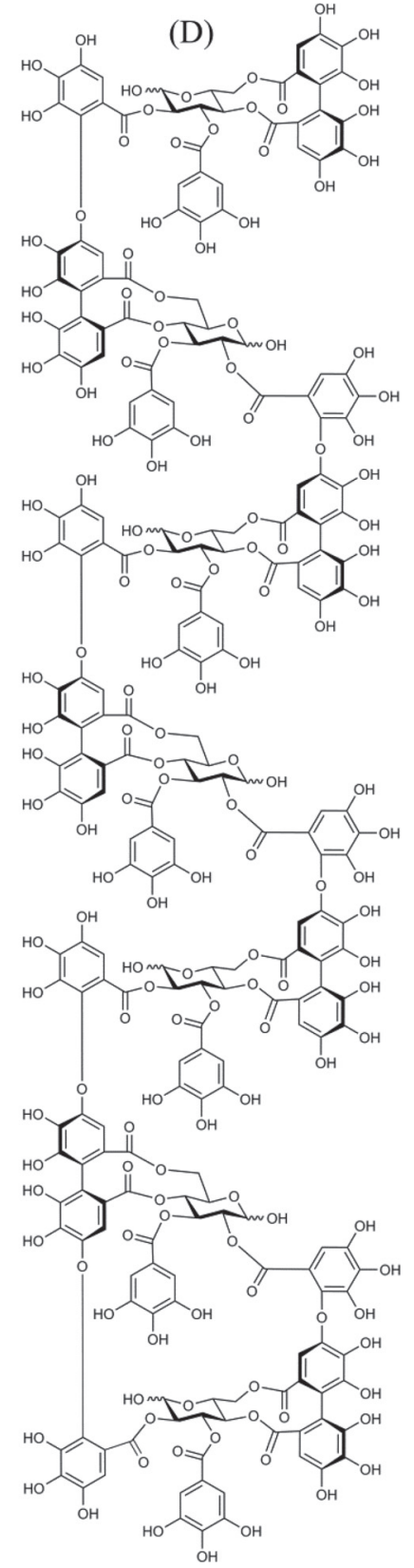

Figure 1. Tellimagrandin I-based oligomeric ellagitannins of Epilobium angustifolium. Monomer: tellimagrandin I (A), dimer: oenothein B (B), trimer: oenothein A (C), and heptamer (D). 
knowledge, no published studies have investigated the activity of pure, individual HT molecules on in vitro ruminal fermentation. In this paper, we endeavored to fill that gap by testing, for the first time, the effects of 6 oligomeric ET isolated from rosebay willowherb (Epilobium angustifolium) in an in vitro model of ruminal fermentation. The objective of the present study was to determine whether the degree of oligomerization of ET had a direct influence on their ability to alter ruminal fermentation.

\section{MATERIALS AND METHODS}

\section{Ellagitannins Isolation and Purification}

Isolation and purification of the oligomeric ellagitannins (ET) have been thoroughly described in our previous work (Baert et al., 2015). Briefly, fresh willowherb (Epilobium angustifolium) flowers $(2 \mathrm{~kg}$ ) were extracted with an acetone/water mixture (4:1, vol/vol). The aqueous extract was lyophilized and then mixed to Sephadex LH-20 gel in water (GE Healthcare, Uppsala, Sweden). Elution was carried out in a Büchner funnel using a water/methanol/acetone solvent system of increasing lipophilicity. The fraction, which was eluted by acetone/water $(4: 1, \mathrm{vol} / \mathrm{vol})$, had the largest content of oligomeric ET and was thus lyophilized for additional fractionations. A preliminary separation of the oligomeric ET was first conducted by column chromatography with Sephadex LH-20. The Sephadex fractions were then purified by several fractionation steps of preparative HPLC and semi-preparative HPLC. The final purity of the isolated molecules was assessed by ultrahigh-performance liquid chromatography-diode array detector-electrospray ionization-tandem MS (UHPLC-DAD-ESI-MS/MS) and is reported in Table 1. Oligomeric ET that eluted after heptamer (i.e., octamer to, at least, undecamer) were collected and combined in a single fraction that could not be further purified, and thus were labeled polymers.

\section{Cumulative Gas Production in Vitro}

Rumen fluid was collected from 4 rumen-cannulated nonlactating Holstein-Friesian dairy cows. Donor cows were fed on a mixture of grass silage and maize silage (on a 1:1 ratio, based on DM). The nutrient composition of the mixture was the following: $\mathrm{CP}=105 \mathrm{~g} /$ $\mathrm{kg}$ of $\mathrm{DM} ; \mathrm{NDF}=481 \mathrm{~g} / \mathrm{kg}$ of DM; $\mathrm{ADF}=260 \mathrm{~g} / \mathrm{kg}$ of DM; $\mathrm{ADL}=22 \mathrm{~g} / \mathrm{kg}$ of DM; starch $=187 \mathrm{~g} / \mathrm{kg}$ of DM. The animals were fed once per day in the morning. The diet was provided ad libitum, and animals had free access to water at all times. The handling of the animals was approved by the Institutional Animal Care and Use Committee of Wageningen University (Wageningen, the Netherlands) and was done in accordance with the European Union directive 2010/63/ EU and Dutch legislation on the use of experimental animals. Rumen fluid was collected before the morning feeding into prewarmed and $\mathrm{CO}_{2}$-flushed thermos flasks and transported quickly to the laboratory. Two independent mixtures (referred to as $\mathrm{A}$ and $\mathrm{B}$ for the remainder of this article) were then created by mixing equal volumes of fluid from 2 cows. Rumen fluid mixtures were filtered through 2 layers of cheesecloth into 2 separate glass bottles and kept under a constant flow of $\mathrm{CO}_{2}$ and in a $39^{\circ} \mathrm{C}$ water bath. Rumen fluid mixtures $\mathrm{A}$ and $\mathrm{B}$ were then diluted in a 1:15 ratio ( $\mathrm{vol} / \mathrm{vol})$ with a freshly prepared buffer medium following the procedure of Williams et al. (2005) and Pellikaan et al. (2011b). The buffer medium that we used in this study was a slightly modified version of that described by Williams et al. (2005) from which we only removed the cysteine.

Gas production was measured using an automated gas production system as described by Cone et al. (1996) and further modified by Pellikaan et al. (2011a) to allow headspace sampling for measurement of $\mathrm{CH}_{4}$ concentration. About $250 \mathrm{mg}$ of ryegrass silage $(\mathrm{OM}=$ $874 \mathrm{~g} / \mathrm{kg}$ of DM; CP $=197 \mathrm{~g} / \mathrm{kg}$ of DM; NDF $=459$ $\mathrm{g} / \mathrm{kg}$ of DM; $\mathrm{ADF}=280 \mathrm{~g} / \mathrm{kg}$ of DM; ADL $=21 \mathrm{~g} / \mathrm{kg}$ of DM) was weighed in each bottle (except for 2 blank samples). The bottles were prewarmed at $39^{\circ} \mathrm{C}$ and flushed with $\mathrm{CO}_{2}$ to remove oxygen and were then filled with $30 \mathrm{~mL}$ of buffered rumen fluid. Before sealing the bottles, $1 \mathrm{~mL}$ of ET solution was added to achieve a final concentration in the buffered rumen fluid of $0.1 \mathrm{mM}$ (conversion in $\mathrm{mg} / \mathrm{g}$ of substrate are shown in Table 1 ). Finally, bottles were sealed, connected to the electronic pressure transducer units, and placed in a water bath maintained at $39^{\circ} \mathrm{C}$ with gentle and constant shaking.

Table 1. Purity, molecular weight, and mass concentration of the oligomeric ellagitannins isolated from Epilobium angustifolium

\begin{tabular}{|c|c|c|c|c|c|c|c|}
\hline Item & Dimer & Trimer & Tetramer & Pentamer & Hexamer & Heptamer & Polymers \\
\hline Molar mass $(\mathrm{g} / \mathrm{mol})$ & $1,569.1$ & $2,353.6$ & $3,182.2$ & $3,922.7$ & $4,707.3$ & $5,491.8$ & - \\
\hline Amount per bottle ${ }^{1}$ (mg/g of substrate) & 19.5 & 29.2 & 38.9 & 48.6 & 58.4 & 68.1 & $87.5^{2}$ \\
\hline
\end{tabular}

${ }^{1}$ Equivalent to a concentration of $0.1 \mathrm{~m} M$ in $31 \mathrm{~mL}$ of buffered rumen fluid.

${ }^{2}$ Calculated on the basis of the molar mass of the nonamer $(7,060 \mathrm{~g} / \mathrm{mol})$. 
Gas production was recorded over $72 \mathrm{~h}$. The choice of the operating concentration of $0.1 \mathrm{~m} M$ was made on the basis of a preliminary experiment (unpublished data) in which dimer and trimer were tested (with the same experimental setup) at 0.5, 0.2, 0.1, 0.05, and 0.02 $\mathrm{m} M$. The concentration $0.1 \mathrm{~m} M$ was chosen because it induced a moderate inhibition of total gas and $\mathrm{CH}_{4}$ production.

The experiment followed a randomized block design that consisted of 2 blocks (one for each rumen fluid mixture). Each block consisted of 1 blank (i.e., buffered rumen fluid alone), 5 controls (i.e., buffered rumen fluid + substrate without ET), and 4 replicates for dimer, trimer, tetramer, pentamer, hexamer, and polymers (i.e., buffered rumen fluid + substrate + ET). In the case of heptamer, only 3 replicates from one source of rumen fluid were performed because the purification process of heptamer was difficult and only yielded a limited amount of pure compound. Total cumulative gas production was expressed in milliliters per gram of OM.

\section{Cumulative Methane Production}

Methane concentration in the headspace of the fermentation bottles was measured at $0,2,4,6,9,11,23$, $27,32,36,48,52,60$, and $72 \mathrm{~h}$. The headspace was sampled via a side port sealed with a screw cap and an air-tight septum, and $\mathrm{CH}_{4}$ was quantified by gas chromatography as described in Hatew et al. (2016).

\section{Nutrient Analysis}

The chemical composition of the substrate was determined according to the procedures described by Hatew et al. (2016).

\section{Volatile Fatty Acid Determination}

After $72 \mathrm{~h}$ of incubation, samples from the fermentation fluid were collected and analyzed for VFA. From each bottle, $600 \mu \mathrm{L}$ of fluid was pipetted and mixed with $600 \mu \mathrm{L}$ of an internal standard solution containing $19.68 \mathrm{mM}$ of 4 -methylpentanoic acid in $0.42 \%$ aqueous ortho-phosphoric acid. Samples were vigorously shaken, centrifuged at $14,000 \times g$ for 5 min at $20^{\circ} \mathrm{C}$, and the clear supernatants were pipetted into crimp neck vials. Analyses were carried out by gas chromatography coupled with a flame ionization detector. The column was a HP-FFAP (30 m, $0.53 \mathrm{~mm}$ i.d., $1.00 \mu \mathrm{m}$ film thickness) from Agilent Technologies (Santa Clara, CA). The oven temperature program started at $80^{\circ} \mathrm{C}$ for $1 \mathrm{~min}$, then increased to $120^{\circ} \mathrm{C}$ at a rate of $20^{\circ} \mathrm{C} / \mathrm{min}$ and further increased at a rate of $6.1^{\circ} \mathrm{C} / \mathrm{min}$ to $205^{\circ} \mathrm{C}$ and remained at that temperature for 2 min. Split injection mode was used with a split ratio of 1:9 and an injection volume of $0.1 \mu \mathrm{L}$. Injection temperature was set at $260^{\circ} \mathrm{C}$. Dihydrogen was used as carrier gas at a constant pressure of $25 \mathrm{kPa}$. The base temperature of the detector was set at $260^{\circ} \mathrm{C}$. Each sample was analyzed in duplicate for determination of acetic acid, propionic acid, butyric acid, isobutyric acid (2-methylpropanoic acid), valeric acid, and isovaleric acid (3-methylbutanoic acid). Concentrations of those analytes in the samples were determined by using an external calibration solution, which was analyzed before and after every set of 10 samples. Internal standard (4-methylpentanoic acid) was used for correction of peak area and for peak identification of the individual VFA acetate $(\mathbf{C 2})$, propionate $(\mathbf{C 3})$, butyrate (C4), and valerate (C5), and the branchedchain VFA isobutyrate (iC4) and isovalerate (iC5).

\section{Ammonia Nitrogen Analyses}

After $72 \mathrm{~h}$ of incubation, $750 \mu \mathrm{L}$ of fluid was pipetted from each bottle and deproteinized by addition of $750 \mu \mathrm{L}$ of a trichloroacetic acid solution $(100 \mathrm{~g} / \mathrm{L}$ of trichloroacetic acid, neutralized with $\mathrm{NaOH}$ ). Samples were then centrifuged for $10 \mathrm{~min}$ at $14,000 \times g$ at $20^{\circ} \mathrm{C}$. Ammonia concentration was determined from the supernatant by colorimetry (Weatherburn, 1967) using a UV spectrophotometer (Evolution 201, Thermo Scientific, Waltham, MA). Each sample was analyzed in duplicate, and the retained value for the concentration of $\mathrm{NH}_{3}-\mathrm{N}$ was the average of the 2 determinations.

\section{Curve Fitting and Statistical Calculations}

The cumulative production of $\mathrm{CH}_{4}$ over $72 \mathrm{~h}$ was calculated using the method described by Pellikaan et al. (2011b). Briefly, the $\mathrm{CH}_{4}$ concentration in the headspace was plotted against time and fitted with the modified monophasic nonlinear Michaelis-Menten equation described by Groot et al. (1996). The kinetic parameters were then used to calculate the $\mathrm{CH}_{4}$ concentration at every valve opening. Finally, the cumulative $\mathrm{CH}_{4}$ production over $72 \mathrm{~h}$ was the sum of the $\mathrm{CH}_{4}$ accumulated in the headspace plus the amounts vented out at every valve opening. Results were expressed as milliliters of $\mathrm{CH}_{4}$ per gram of OM. The evolution of $\mathrm{CH}_{4}$ share in the total gas produced was also calculated. Curve-fitting operations were performed using the nonlinear least squares regression procedure NLIN from SAS (2010, SAS Institute Inc., Cary, NC). Outliers were excluded from the results when their total gas or methane production differed from the average value by more than 2 standard deviations. In this experiment the outliers were 1 replicate in the control group of each 
inoculum (A and B), 1 replicate in the group dimer/ inoculum $\mathrm{A}$, and 1 replicate in the group treated with heptameric ET.

Statistical analyses were performed using the software R (R Core Team, 2016). A linear mixed-effects model (from the lme4 package) was used to compare the influence of the different treatments on gas production, $\mathrm{CH}_{4}, \mathrm{VFA}, \mathrm{pH}$, and $\mathrm{NH}_{3} \mathrm{~N}$. The model included treatment (control and ET) as fixed effect and rumen fluid mixture as random effect. Pairwise comparison of least squares means was performed using Tukey's multiple comparison. Significance was declared at $P$ $\leq 0.05$. Additionally, orthogonal polynomial contrasts were calculated to assess the linear and quadratic effects of oligomer size (from dimer to hexamer) on all the measured variables. Data from heptamer were excluded from this model because the small number of replicates and the fact that it was only tested with one source of rumen fluid would unfairly influence the model. We used principal component analysis (PCA) to visualize the differences between treatments and rumen fluid mixtures.

\section{RESULTS}

\section{Effect of the Rumen Fluid Source}

Fluid A produced more $\mathrm{CH}_{4}$ than fluid $\mathrm{B}$ with all treatments, at all time points $(P<0.001)$. The differences in average $\mathrm{CH}_{4}$ production between fluid $\mathrm{A}$ and B fluctuated with time but were seen to be as high as $9 \mathrm{~mL} / \mathrm{g}$ of $\mathrm{OM}$ in bottles treated with dimer at $72 \mathrm{~h}$. Control and dimer were the most affected by the effect of rumen fluid source, and the gap between A and B tended to be smaller with larger oligomers (Figure 3). We also observed higher values for isovaleric acid $(P=$ $0.004)$ and $\mathrm{NH}_{3}-\mathrm{N}(P=0.006)$ with inoculum A compared with inoculum B. All other measured parameters were statistically identical between inocula A and B.

\section{Effect on Gas and Methane Production}

The kinetics of gas and $\mathrm{CH}_{4}$ production for each treatment is represented in Figure 2. All the tested ET decreased total gas production at $6,12,24,48$, and 72 h compared with control (Table 2). Already after $6 \mathrm{~h}$ of incubation, all the ET-containing media showed a drastically reduced average gas production compared with the ET-free media, ranging from $33 \%$ with dimer to $91 \%$ with the polymers. Results (Table 2) show a linear effect $(P<0.001)$ of oligomer size on total gas production.

All the tested ET produced a reduction of $\mathrm{CH}_{4}$ production compared with the controls (Table 2). The extent of that reduction was larger during the first 12 $\mathrm{h}$ of fermentation and tended to decrease over time. Dimer, for instance, decreased $\mathrm{CH}_{4}$ production by $70 \%$ compared with the controls at $t=12 \mathrm{~h}$, but that decrease was only $48 \%$ at $t=48 \mathrm{~h}$. The same trend was observed with all the other ET. Methane production decreased quadratically when oligomer size increased. Dimer induced the smallest inhibition of $\mathrm{CH}_{4}$ production, but there was little to no difference between all other ET (Table 2).

The share of $\mathrm{CH}_{4}$ in the controls increased steadily over time, rising from about $2 \%$, at the beginning of the experiment, to $13 \%$ at $72 \mathrm{~h}$ (Figure 2). In the presence of $\mathrm{ET}$, however, the proportion of $\mathrm{CH}_{4}$ increased during the first 4 to $5 \mathrm{~h}$ and dropped abruptly (except for dimer) to reach a minimum of about 1 to $2 \%$ around 12 $\mathrm{h}$. It then remained constant until $40 \mathrm{~h}$, at which point it started to increase again. The oligomer size had a quadratic effect on the share of $\mathrm{CH}_{4}$ when considering time points beyond $12 \mathrm{~h}$ (Table 2). Similarly to what we observed with $\mathrm{CH}_{4}$ production, all ET diminished the proportion of $\mathrm{CH}_{4}$ (after $12 \mathrm{~h}$ ). Dimer was the least effective molecule, and all the other ET (trimer to polymers) produced the same effect on the proportion of $\mathrm{CH}_{4}$ to total gas (Table 2).

\section{Effect on Volatile Fatty Acid Concentration}

All the tested ET, except dimer, induced a decrease in total VFA concentration compared with the controls. Total VFA concentration declined linearly $(P<0.001)$ as the size of the oligomers increased (Table 3). Acetate concentration was decreased by all the tested compounds. This decrease ranged from $10 \%$ with dimer, to $42 \%$ with polymers and showed a linear relationship with oligomer size. However, the proportion of acetate to total VFA within each treatment showed little variability and only ranged from 56 to $51 \%$. Dimer and tetramer increased the concentration of propionic acid by $17 \%$ compared with the controls. In addition, all ET increased the proportion of propionate to total VFA by 6 to 10 percentage points compared with the value of controls (Table 3 ). Butyric acid concentration was reduced by all the ET. This reduction was as high as $69 \%$ with polymers, and dimer showed, again, the weakest effect. Valerate and isobutyrate concentrations exhibited relatively similar patterns as both decreased linearly as oligomer size increased. Moreover, the share of butyrate and valerate in total VFA was unaffected by ET. The concentration of isovaleric acid was decreased by all ET. Dimer produced the weakest effect, whereas all the other compounds induced a similar diminution of isolvalerate concentration. Oligomer size had a quadratic effect on the concentration of isovalerate. 
(A)
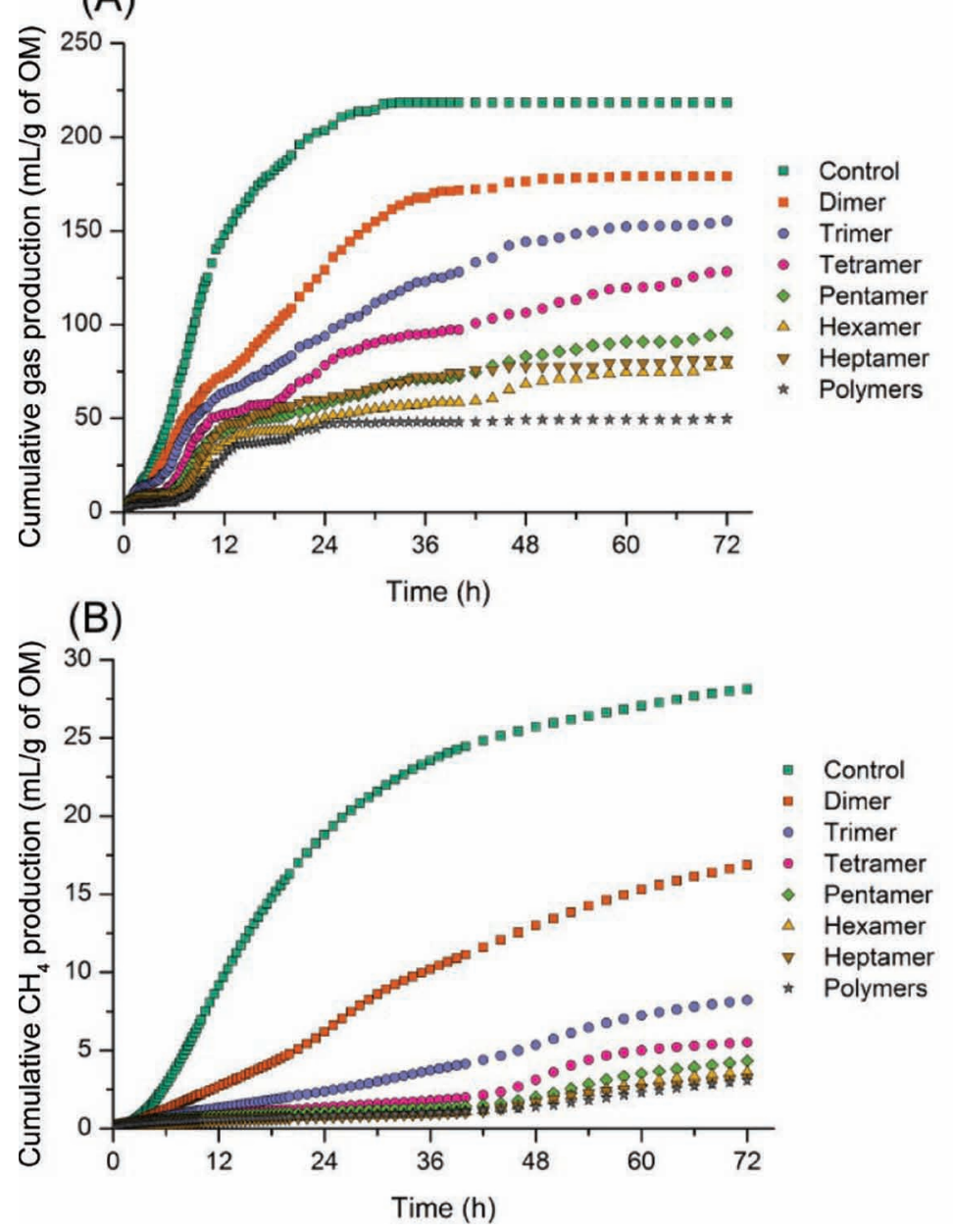

- Control

- Dimer

- Trimer

- Tetramer

- Pentamer

^ Hexamer

- Heptamer

* Polymers

Figure 2. Kinetics of in vitro total gas production (A), methane production (B), and methane proportion in total gas (C) in the presence of oligomeric ellagitannins versus control. Insert (D) shows an enhanced view of methane proportion during the first $12 \mathrm{~h}$. Color version available online.

\section{Effect on Ammonia Nitrogen and $\mathrm{pH}$}

All ET caused a decrease in $\mathrm{NH}_{3}-\mathrm{N}$ concentration compared with the controls. Oligomer size showed a quadratic effect on $\mathrm{NH}_{3}-\mathrm{N}$ concentration. The strongest decrease was observed with the average-sized oligomers (trimer, tetramer, and pentamer), whereas the weakest effects were observed with dimer and polymers, the smallest and largest oligomers tested, respectively. The $\mathrm{pH}$ of the medium after $72 \mathrm{~h}$ of incubation showed a positive linear relationship with oligomer size. However, only pentamer, hexamer, and polymers significantly increased the $\mathrm{pH}$ compared with the value of controls.

\section{DISCUSSION}

The marked linear relationship between total gas production and the degree of oligomerization of ET
(Table 2) undeniably demonstrates that ET of different sizes have different levels of activity toward ruminal fermentation in vitro. Moreover, our results show that the capacity of those molecules to reduce total gas production in vitro is directly proportional to their size, at least for the tested range (i.e., dimer to hexamer). It has been previously demonstrated that, with such an in vitro system, an important part of the recorded gas production consists of $\mathrm{CO}_{2}$ released from the bicarbonate buffer upon buffering the VFA that are synthesized throughout the fermentation of substrate (Beuvink and Spoelstra, 1992; Blümmel et al., 1999). Therefore, in this experiment, the ability of oligomeric ET to inhibit total gas production reflects - to a large extent - their ability to decrease VFA production. That assumption is evidenced by the strong linear relationship between total gas produced at $72 \mathrm{~h}$ and total VFA $\left(\mathrm{R}^{2}=0.75, P\right.$ $<0.001)$. Additionally, the greater $\mathrm{pH}$ values observed 


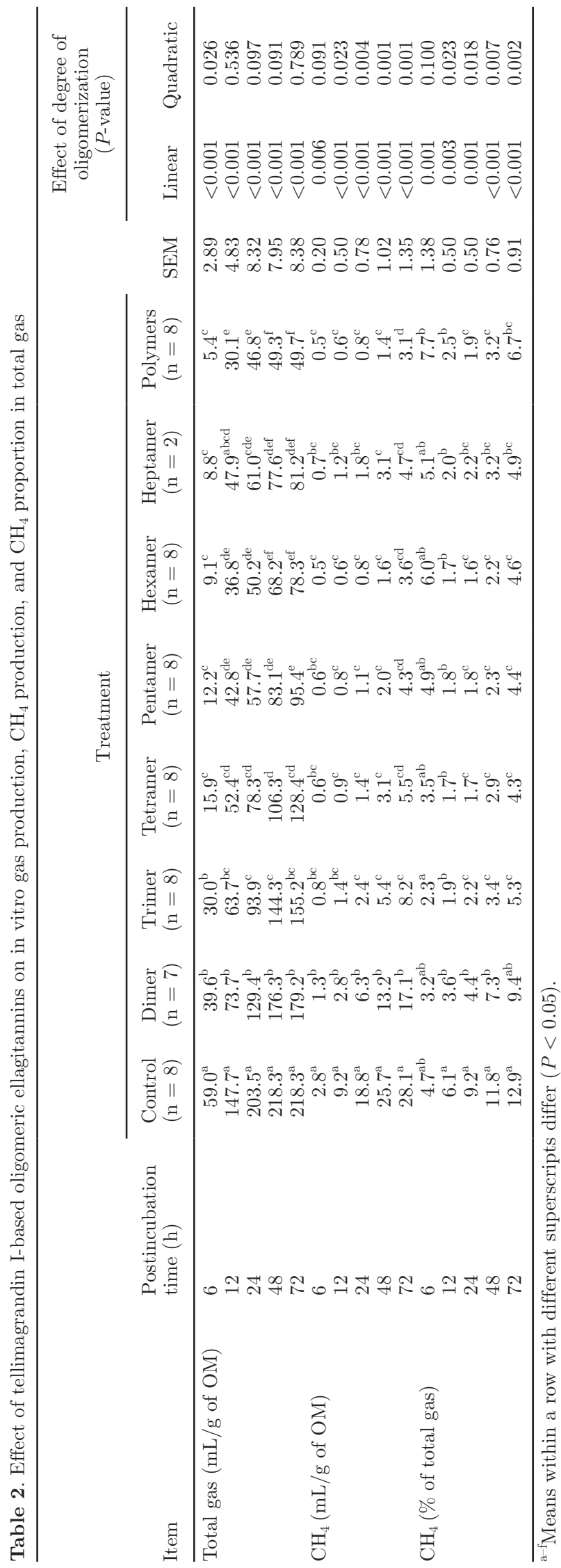

with larger ET (Table 3) also support that assumption because $\mathrm{pH}$ in vitro is highly dependent on VFA production (Wu et al., 2015). This association is also highlighted by PCA (Figure 3), where the loadings of total VFA and $\mathrm{pH}$ on $\mathrm{PC} 1$ and $\mathrm{PC} 2$ are opposite. According to Blümmel et al. (1997), in vitro gas production accurately reflects OM degradation. We can therefore assume that, in our experiment, the decrease in gas production observed with ET compared with control (Table 2) is an indicator of inhibition of $\mathrm{OM}$ fermentation by ET. This assumption is further supported by other experiments involving ET-rich plant extracts (Bhatta et al., 2009; Pellikaan et al., 2011b). It is not possible to conclude, however, whether the decreased OM fermentation was due to a direct effect of ET on cellulolytic bacteria and ciliate protozoa or to a decrease of fiber degradability through tannin-fiber binding, or both.

Decreased fiber degradation and OM fermentation inevitably impede $\mathrm{CH}_{4}$ formation by slowing down the production rates of $\mathrm{H}_{2}$ and the reduced coenzyme $\mathrm{NADH}$, both of which are necessary for $\mathrm{CH}_{4}$ synthesis by methanogens (McAllister et al., 1996; Moss et al., 2000). Therefore, assuming that the tested compounds had no other activity than the alteration of OM fermentation, the decline in $\mathrm{CH}_{4}$ production should closely follow that of total gas, and consequently, the $\mathrm{CH}_{4}$ / total gas ratio should remain relatively constant across all the tested ET. However, we measured a decrease in $\mathrm{CH}_{4}$ production by ET that was of a larger magnitude than the abatement in total gas production. As an illustration, oenothein $\mathrm{B}$, which was the least potent molecule tested, reduced $\mathrm{CH}_{4}$ production at $24 \mathrm{~h}$ by $67 \%$ and total gas production by only $36 \%$ at the same time point (Table 1). This result is mirrored by the $\mathrm{CH}_{4} /$ total gas ratio, which showed, at $24 \mathrm{~h}$ with oenothein B, a $53 \%$ reduction compared with control. Together, these pieces of evidence indicate that the mitigation of $\mathrm{CH}_{4}$ production by TI-based oligomeric ET cannot be solely attributed to a general inhibition of OM fermentation. The tested compounds therefore have a specific effect on methanogenesis and the strength of that effect does not show a simple linear relationship with the size of the molecule at the tested concentration of $0.1 \mathrm{mM}$ (Table 2). Nevertheless, in the light of this experiment alone, we cannot rule out the possibility of a linear relationship between the inhibition of methanogenesis and oligomer size. The average values of $\mathrm{CH}_{4}$ production observed with trimer to polymers are extremely low and show no statistical difference (Table 1). This most likely indicates that the maximum inhibition was already reached with $0.1 \mathrm{~m} M$ of trimer, thus precluding us from seeing any potential linear effect. This could 
BAERT ET AL.

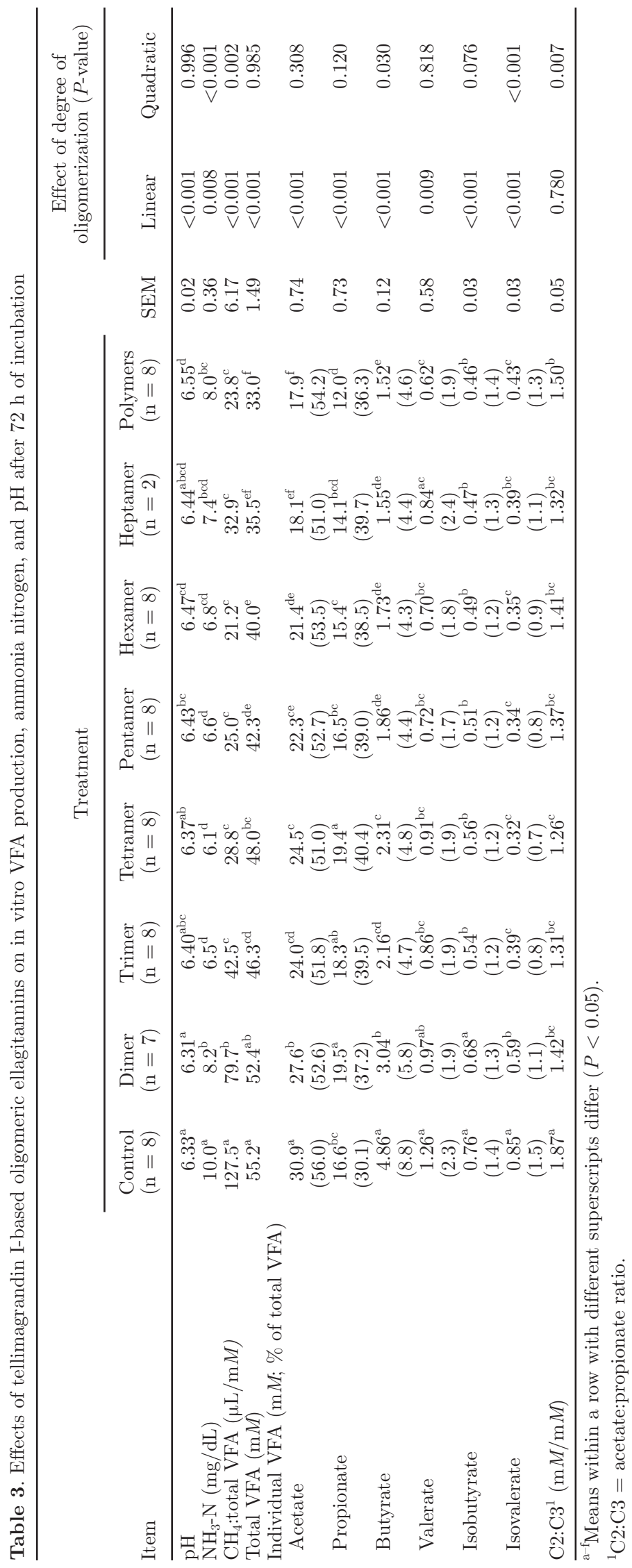


be verified in a future experiment by testing lower concentrations.

Willowherb oligomeric ET induced a decrease in the final concentration of all the individual VFA, with the sole exception of propionic acid. Interestingly, propionate concentration was increased by dimer and tetramer and was only decreased by polymers. Previous in vitro studies have reported an increase in the proportion of propionate with tannins (Bhatta et al., 2009; Pellikaan et al., 2011b; Hassanat and Benchaar, 2013). However, this is, to the best of our knowledge, the first report of HT increasing the absolute molar concentration of propionate in vitro. In the rumen, methanogenesis and propionate synthesis are 2 competing pathways for the regeneration of the oxidized coenzyme $\mathrm{NAD}^{+}$(Moss et al., 2000). Those 2 reactions consume $\mathrm{H}_{2}$ and thus contribute to maintain a low $\mathrm{H}_{2}$ partial pressure in the rumen, which is necessary for the normal functioning of microbial enzymes involved in electron transfer reactions (Morgavi et al., 2010). When methanogenesis is inhibited, $\mathrm{H}_{2}$ is subsequently re-channeled toward the production of propionic acid. This could explain why, unlike the other VFA, the concentration of propionate, in our experiment, was not decreased (and even increased with 2 compounds) in spite of the general inhibition of OM fermentation by ET. This result reinforces the hypothesis of the specific activity of willowherb oligomeric ET against methanogens. The observation of the absolute concentration of propionate, however, cannot be used alone to draw conclusions about the influence of the degree of oligomerization of ET on their anti-methanogenic activity. The acetate/propionate $(\mathrm{C} 2: \mathrm{C} 3)$ ratio is a more suitable indicator for that purpose because it reveals the strength of shift in VFA production caused by the inhibition of methanogenesis. In our experiment the $\mathrm{C} 2$ :C3 ratio showed a quadratic relationship with oligomer size, and was minimal with the tetramer and maximal with polymers (Table 3 ). This finding was also emphasized by PCA, where dimer, trimer, and tetramer show the lowest scores on PC2 (Figure 3), which was constructed mainly by the contributions of $\mathrm{C} 3$ and $\mathrm{C} 2$ :C3 ratio. These results indicate that small to average-sized oligomers exert stronger inhibition on methanogens than large oligomers.

Willowherb oligomeric ET also exhibited some activity toward ruminal protein degradation. The deamination of AA by ruminal bacteria produces ammonia, and the catabolism (deamination and decarboxylation) of valine and leucine has been shown to produce isobutyr-

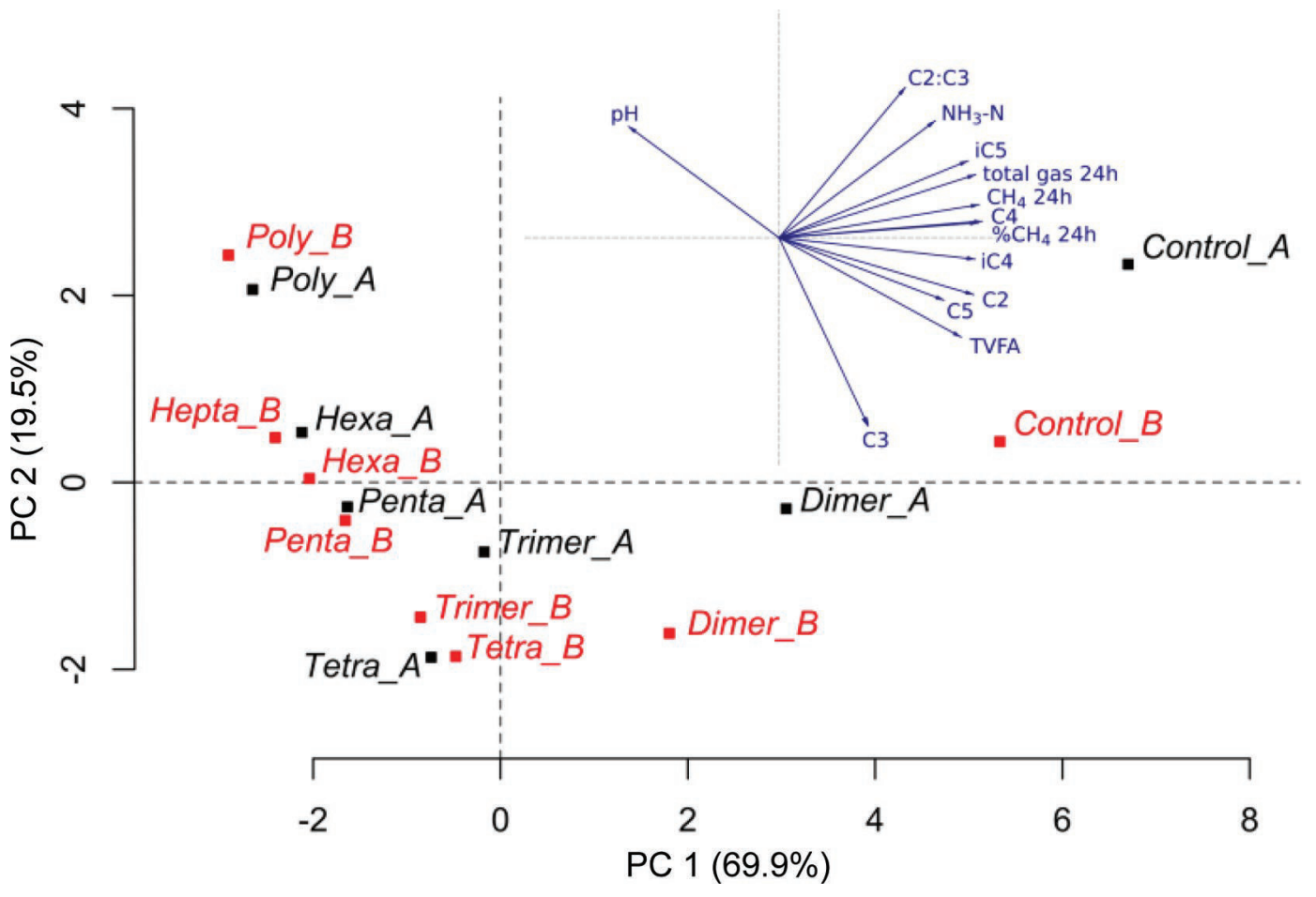

Figure 3. Principal component (PC) analysis biplot showing the score of each treatment on PC1 and PC2 separated by rumen fluid mixtures (A and $\mathrm{B})$, and the loadings of the dependent variables on $\mathrm{PC} 1$ and $\mathrm{PC} 2$. Acetate (C2), propionate (C3), butyrate (C4), valerate (C5), isobutyrate (iC4), isovalerate (iC5), total VFA (TVFA), polymer (Poly), heptamer (Hepta), hexamer (Hex), pentamer (Penta), tetramer (Tetra). Color version available online. 
ate and isovalerate, respectively (Menahan and Schultz, 1964). In our experiment, ET reduced both ammonia nitrogen and branched-chain VFA concentrations compared with the control, thus suggesting an inhibition of microbial protein degradation. This finding agrees with previous in vitro studies on tannin activity (Patra and Saxena, 2011; Hassanat and Benchaar, 2013). Tannins have been shown to bind to proteins, thus decreasing their degradability by microbes or, alternatively, to inhibit directly the activity microbial population (Jones et al., 1994; McSweeney et al., 2001). We observed a clear quadratic relationship between degree of oligomerization and both ammonia nitrogen and isovaleric acid concentration (Table 3). In both cases, the maximum inhibition was recorded with the tetramer. Even though we did not observe any statistical difference between trimer, tetramer, pentamer, hexamer, and heptamer, these results show at least that the aforementioned molecules are more effective at protecting proteins from bacterial degradation in the rumen than dimer and polymers. The weaker effect of dimer could originate from a lower affinity for proteins, as evidenced by Karonen et al. (2015). In this study, authors tested the binding of TI-based oligomeric ET to BSA and revealed that dimer had the lowest binding constant of the whole series. However, the authors also found that polymers had a strong affinity for BSA, similar to that of tetra to heptamer, which is contradictory to our observations. This might be explained by the difference between BSA and proteins that are found in grass silage.

The degree of oligomerization of TI-based ET greatly influences their activity in vitro. But more importantly, this study shows that the effect of size on the activity of ET is more complex than a simple linear relationship and depends on the nature of the targeted mechanism. When considering plant secondary metabolites as a $\mathrm{CH}_{4}$ mitigation strategy in animal production, one should try to minimize their adverse effect on fermentation of feedstuff while seeking a maximal inhibition of methanogenesis. In that respect, our experiment shows that small-sized oligomers are better candidates then large ones, as far as oligomeric ET are concerned. Indeed, dimeric, trimeric, and tetrameric ET produced the strongest inhibition of methanogenesis and the lowest disturbance of OM fermentation and total VFA production. Incidentally, they also happen to be most abundant in the plant (Baert et al., 2015).

\section{CONCLUSIONS}

This study showed that TI-based oligomeric ET decrease $\mathrm{CH}_{4}$ production in vitro. This inhibition was the result of 2 co-occurring mechanisms: a general reduction of gas production, and a specific inhibition of methane production. The first mechanism showed a linear relationship with the degree of oligomerization of ET, whereas the second one was not dependent on the size of the oligomer at the tested concentration. In addition, willowherb oligomeric ET were able to decrease $\mathrm{NH}_{3}-\mathrm{N}$ and branched-chain VFA production, 2 indicators of protein degradation by bacteria. This effect was stronger with average-sized ET (trimer, tetramer, and pentamer) and weaker with small and large oligomeric ET.

\section{ACKNOWLEDGMENTS}

This study was supported by the European Commission (PITN-GA-2011-289377, "LegumePlus" project), the Academy of Finland (Grant no. 258992 to J.-P.S. and 251388 to M.K.), and the Turun Yliopistosäätiö (Turku, Finland). The Strategic Research Grant (Ecological Interactions) to J.-P.S. enabled the use of the UPLC-MS/MS instrument. Saskia van Laar and Michel Breuer (Wageningen University, Wageningen, the Netherlands) are dearly thanked for handling the VFA and $\mathrm{NH}_{3}$ analyses and for their guidance in the laboratory. The authors are grateful to Bayissa Hatew (Wageningen University) for his help with rumen fluid collection. The assistance of John Cone (Wageningen University) in the preparation of the incubation media is gratefully acknowledged. Jorma Kim (University of Turku, Finland) is thanked for his timely assistance in the purification of ellagitannins.

\section{REFERENCES}

Baert, N., M. Karonen, and J.-P. Salminen. 2015. Isolation, characterisation and quantification of the main oligomeric macrocyclic ellagitannins in Epilobium angustifolium by ultra-high performance chromatography with diode array detection and electrospray tandem mass spectrometry. J. Chromatogr. A 1419:26-36. http:// dx.doi.org/10.1016/j.chroma.2015.09.050.

Beuvink, J. M. W., and S. F. Spoelstra. 1992. Interactions between substrate, fermentation end-products, buffering systems and gas production upon fermentation of different carbohydrates by mixed rumen microorganisms in vitro. Appl. Microbiol. Biotechnol. 37:505-509. http://dx.doi.org/10.1007/BF00180978.

Bhatta, R., M. Saravanan, L. Baruah, K. T. Sampath, and C. S. Prasad. 2013. Effect of plant secondary compounds on in vitro methane, ammonia production and ruminal protozoa population. J. Appl. Microbiol. 115:455-465. http://dx.doi.org/10.1111/ jam. 12238 .

Bhatta, R., Y. Uyeno, K. Tajima, A. Takenaka, Y. Yabumoto, I. Nonaka, O. Enishi, and M. Kurihara. 2009. Difference in the nature of tannins on in vitro ruminal methane and volatile fatty acid production and on methanogenic archaea and protozoal populations. J. Dairy Sci. 92:5512-5522. http://dx.doi.org/10.3168/jds.2008-1441.

Blümmel, M., K.-P. Aiple, H. Steingaß, and K. Becker. 1999. A note on the stoichiometrical relationship of short chain fatty acid production and gas formation in vitro in feedstuffs of widely differing 
quality. J. Anim. Physiol. Anim. Nutr. (Berl.) 81:157-167. http:// dx.doi.org/10.1046/j.1439-0396.1999.813205.x.

Blümmel, M., H. P. S. Makkar, and K. Becker. 1997. In vitro gas production: A technique revisited. J. Anim. Physiol. Anim. Nutr. (Berl.) 77:24-34.

Cone, J. W., A. H. van Gelder, G. J. W. Visscher, and L. Oudshoorn. 1996. Influence of rumen fluid and substrate concentration on fermentation kinetics measured with a fully automated time related gas production apparatus. Anim. Feed Sci. Technol. 61:113-128. http://dx.doi.org/10.1016/0377-8401(96)00950-9.

Ducrey, B., A. Marston, S. Göhring, R. W. Hartmann, and K. Hostettmann. 1997. Inhibition of 5 alpha-reductase and aromatase by the ellagitannins oenothein A and oenothein B from Epilobium species. Planta Med. 63:111-114.

Gerber, P. J., H. Steinfeld, B. Henderson, A. Mottet, C. Opio, J. Dijkman, A. Falcucci, and G. Tempio. 2013. Tackling climate change through livestock-A global assessment of emissions and mitigation opportunities. Food and Agriculture Organization of the United Nations (FAO), Rome, Italy.

Groot, J. C. J., J. W. Cone, B. A. Williams, F. M. A. Debersaques, and E. A. Lantinga. 1996. Multiphasic analysis of gas production kinetics for in vitro fermentation of ruminant feeds. Anim. Feed Sci. Technol. 64:77-89. http://dx.doi.org/10.1016/S03778401(96)01012-7.

Hassanat, F., and C. Benchaar. 2013. Assessment of the effect of condensed (acacia and quebracho) and hydrolysable (chestnut and valonea) tannins on rumen fermentation and methane production in vitro. J. Sci. Food Agric. 93:332-339. http://dx.doi.org/10.1002/ jsfa. 5763 .

Hatew, B., E. Stringano, I. Mueller-Harvey, W. H. Hendriks, C. H. Carbonero, L. M. J. Smith, and W. F. Pellikaan. 2016. Impact of variation in structure of condensed tannins from sainfoin (Onobrychis viciifolia) on in vitro ruminal methane production and fermentation characteristics. J. Anim. Physiol. Anim. Nutr. (Berl.) http://dx.doi.org/10.1111/jpn.12336.

Jayanegara, A., G. Goel, H. P. S. Makkar, and K. Becker. 2015. Divergence between purified hydrolysable and condensed tannin effects on methane emission, rumen fermentation and microbial population in vitro. Anim. Feed Sci. Technol. 209:60-68. http://dx.doi. org/10.1016/j.anifeedsci.2015.08.002.

Jayanegara, A., F. Leiber, and M. Kreuzer. 2012. Meta-analysis of the relationship between dietary tannin level and methane formation in ruminants from in vivo and in vitro experiments. J. Anim. Physiol. Anim. Nutr. (Berl.) 96:365-375. http://dx.doi. org/10.1111/j.1439-0396.2011.01172.x.

Johnson, K. A., and D. E. Johnson. 1995. Methane emissions from cattle. J. Anim. Sci. 73:2483-2492.

Jones, G. A., T. A. McAllister, A. D. Muir, and K.-J. Cheng. 1994. Effects of sainfoin (Onobrychis viciifolia Scop.) condensed tannins on growth and proteolysis by four strains of ruminal bacteria. Appl. Environ. Microbiol. 60:1374-1378.

Kamra, D. N., N. Agarwal, and L. C. Chaudhary. 2006. Inhibition of ruminal methanogenesis by tropical plants containing secondary compounds. Int. Congr. Ser. 1293:156-163. http://dx.doi. org/10.1016/j.ics.2006.02.002.

Karonen, M., J. Loponen, V. Ossipov, and K. Pihlaja. 2004. Analysis of procyanidins in pine bark with reversed-phase and normal-phase high-performance liquid chromatography-electrospray ionization mass spectrometry. Anal. Chim. Acta 522:105-112. http://dx.doi. org/10.1016/j.aca.2004.06.041

Karonen, M., M. Oraviita, I. Mueller-Harvey, J. P. Salminen, and R. J. Green. 2015. Binding of an oligomeric ellagitannin series to bovine serum albumin (BSA): Analysis by isothermal titration calorimetry (ITC). J. Agric. Food Chem. 63:10647-10654. http://dx.doi. org/10.1021/acs.jafc.5b04843.

Lönnrot, E., K. Linnilä, S. Savikko, and T. Lempiäinen. 2002. Elias Lönnrotin Flora Fennica. Vol. 3. Oy Amanita Ltd., Helsinki, Finland.

Mansoor, K. A., K. Z. Matalka, F. S. Qa'dan, R. Awad, and M. Schmidt. 2015. Two new proanthocyanidin trimers isolated from
Cistus incanus L. demonstrate potent anti-inflammatory activity and selectivity to cyclooxygenase isoenzymes inhibition. Nat. Prod. Res. http://dx.doi.org/10.1080/14786419.2015.1089242.

McAllister, T. A., K.-J. Cheng, E. K. Okine, and G. W. Mathison. 1996. Dietary, environmental and microbiological aspects of methane production in ruminants. Can. J. Anim. Sci. 76:231-243. http://dx.doi.org/10.4141/cjas96-035.

McSweeney, C. S., B. Palmer, D. M. McNeill, and D. O. Krause. 2001. Microbial interactions with tannins: Nutritional consequences for ruminants. Anim. Feed Sci. Technol. 91:83-93. http://dx.doi. org/10.1016/S0377-8401(01)00232-2.

Menahan, L. A., and L. H. Schultz. 1964. Metabolism of leucine and valine within the rumen. J. Dairy Sci. 47:1080-1085. http://dx.doi. org/10.3168/jds.S0022-0302(64)88849-4.

Morgavi, D. P., E. Forano, C. Martin, and C. J. Newbold. 2010. Microbial ecosystem and methanogenesis in ruminants. Animal 4:10241036. http://dx.doi.org/10.1017/S1751731110000546.

Moss, A. R., J. Jouany, and J. Newbold. 2000. Methane production by ruminants: Its contribution to global warming. Ann. Zootech. 49:231-253.

Mueller-Harvey, I. 2001. Analysis of hydrolysable tannins. Anim. Feed Sci. Technol. 91:3-20. http://dx.doi.org/10.1016/S03778401(01)00227-9.

Mueller-Harvey, I. 2006. Unravelling the conundrum of tannins in animal nutrition and health. J. Sci. Food Agric. 86:2010-2037. http:// dx.doi.org/10.1002/jsfa.2577.

O'Mara, F. P. 2011. The significance of livestock as a contributor to global greenhouse gas emissions today and in the near future. Anim. Feed Sci. Technol. 166-167:7-15. http://dx.doi.org/10.1016/j. anifeedsci.2011.04.074.

Patra, A. K. 2012. Enteric methane mitigation technologies for ruminant livestock: A synthesis of current research and future directions. Environ. Monit. Assess. 184:1929-1952. http://dx.doi. org/10.1007/s10661-011-2090-y.

Patra, A. K., and J. Saxena. 2010. A new perspective on the use of plant secondary metabolites to inhibit methanogenesis in the rumen. Phytochemistry 71:1198-1222. http://dx.doi.org/10.1016/j. phytochem.2010.05.010.

Patra, A. K., and J. Saxena. 2011. Exploitation of dietary tannins to improve rumen metabolism and ruminant nutrition. J. Sci. Food Agric. 91:24-37. http://dx.doi.org/10.1002/jsfa.4152.

Pellikaan, W. F., W. H. Hendriks, G. Uwimana, L. J. G. M. Bongers, P. M. Becker, and J. W. Cone. 2011a. A novel method to determine simultaneously methane production during in vitro gas production using fully automated equipment. Anim. Feed Sci. Technol. 168:196-205. http://dx.doi.org/10.1016/j.anifeedsci.2011.04.096.

Pellikaan, W. F., E. Stringano, J. Leenaars, D. J. G. M. Bongers, S. van Schuppen-van Laar, J. Plant, and I. Mueller-Harvey. 2011b. Evaluating effects of tannins on extent and rate of in vitro gas and $\mathrm{CH} 4$ production using an automated pressure evaluation system (APES). Anim. Feed Sci. Technol. 166-167:377-390. http:// dx.doi.org/10.1016/j.anifeedsci.2011.04.072.

Quideau, S. 2013. Plant polyphenols. Page 2 in eLS. John Wiley \& Sons Ltd., Chichester, UK.

R Core Team. 2016. R: A language and environment for statistical computing. R Foundation for Statistical Computing, Vienna, Austria.

Saminathan, M., C. C. Sieo, N. Abdullah, C. M. V. L. Wong, and Y. W. Ho. 2015. Effects of condensed tannin fractions of different molecular weights from a Leucaena leucocephala hybrid on in vitro methane production and rumen fermentation. J. Sci. Food Agric. 95:2742-2749. http://dx.doi.org/10.1002/jsfa.7016.

Schofield, P., D. M. Mbugua, and A. N. Pell. 2001. Analysis of condensed tannins: A review. Anim. Feed Sci. Technol. 91:21-40.

Śliwiński, B. J., C. R. Soliva, A. Machmüller, and M. Kreuzer. 2002. Efficacy of plant extracts rich in secondary constituents to modify rumen fermentation. Anim. Feed Sci. Technol. 101:101-114. http://dx.doi.org/10.1016/S0377-8401(02)00139-6.

Tavendale, M. H., L. P. Meagher, D. Pacheco, N. Walker, G. T. Attwood, and S. Sivakumaran. 2005. Methane production from 
in vitro rumen incubations with Lotus pedunculatus and Medicago sativa, and effects of extractable condensed tannin fractions on methanogenesis. Anim. Feed Sci. Technol. 123-124:403-419. http://dx.doi.org/10.1016/j.anifeedsci.2005.04.037.

Theodoridou, K., J. Aufrère, V. Niderkorn, D. Andueza, A. Le Morvan, F. Picard, and R. Baumont. 2011. In vitro study of the effects of condensed tannins in sainfoin on the digestive process in the rumen at two vegetation cycles. Anim. Feed Sci. Technol. 170:147159. http://dx.doi.org/10.1016/j.anifeedsci.2011.09.003.

US Environmental Protection Agency. 2015. Inventory of U.S. Greenhouse Gas Emissions and Sinks: 1990-2013. Washington, DC.

Waghorn, G. C., M. H. Tavendale, and D. R. Woodfield. 2002. Methanogenesis from forages fed to sheep. Proc. New Zeal. Grassl. Assoc. 64:159-165.

Weatherburn, M. W. 1967. Phenol-hypochlorite reaction for determination of ammonia. Anal. Chem. 39:971-974. http://dx.doi. org/10.1021/ac60252a045.
Williams, B. A., M. W. Bosch, H. Boer, M. W. A. Verstegen, and S. Tamminga. 2005. An in vitro batch culture method to assess potential fermentability of feed ingredients for monogastric diets. Anim. Feed Sci. Technol. 123-124:445-462. http://dx.doi. org/10.1016/j.anifeedsci.2005.04.031.

Woodward, S. L., G. C. Waghorn, M. J. Ulyatt, and K. R. Lassey. 2001. Early indications that feeding Lotus will reduce methane emissions from ruminants. Proc. N.Z. Soc. Anim. Prod. 61:23-26.

Wu, H., Q. Meng, and Z. Yu. 2015. Effect of $\mathrm{pH}$ buffering capacity and sources of dietary sulfur on rumen fermentation, sulfide production, methane production, sulfate reducing bacteria, and total Archaea in in vitro rumen cultures. Bioresour. Technol. 186:25-33. http://dx.doi.org/10.1016/j.biortech.2015.02.110. 